\title{
Deals that make sense
}

\section{By valuing and structuring their deals appropriately, biotechnology companies can earn higher returns, maintain greater control of intellectual property, and strengthen their partnerships with pharmaceutical companies.}

\author{
Alexander Moscho, Regina A. Hodits, Friedemann Janus, and Josef M.E. Leiter
}

Biotechnology companies not only need intellectual property (IP) portfolios that demonstrate technological know-how and/or product superiority over competitors, they also require innovative business development skills. In an environment where accelerating technological life cycles can erode competitive advantages in less than half a year, a thoughtful and methodical approach for negotiating deals is becoming more important than ever.

\section{Mutually beneficial}

Deal-making opportunities for biotechnology companies remain plentiful because pharmaceutical companies are under increasing pressure to fortify their market capitalizations by ensuring healthy pipelines of new products. Most pharmaceutical companies are currently experiencing a shortfall of new chemical entities at a time when they need to demonstrate significant product growth rates and increase their stock prices so as to succeed in the current merger and acquisition climate.

Many biotechnology firms cannot take advantage of this high demand for their products, however, because they do not have the business experience necessary to structure the best deals. They usually earn less in royalties than their contribution warrants and give away too much in terms of IP- a situation that hurts both them and their pharmaceutical partners over the long term.

To negotiate optimal deals with development partners, biotechnology companies must focus on the two critical areas of fairly valuing the contributions of each partner in the deal, and structuring appropriate control of IP rights. Deals that reflect fair valuations and appropriate intellectual control benefit both partners by laying the foundation for lucrative and successful cooperation over the long term.

Regina A. Hodits, Friedemann Janus, and Alexander Moscho are associates, and Josef M.E. Leiter is a principal at McKinsey New Venture, Prinzregentenstraße 22, Munich, Germany(alexander_moscho@mckinsey.com; josef_leiter@mckinsey.com).

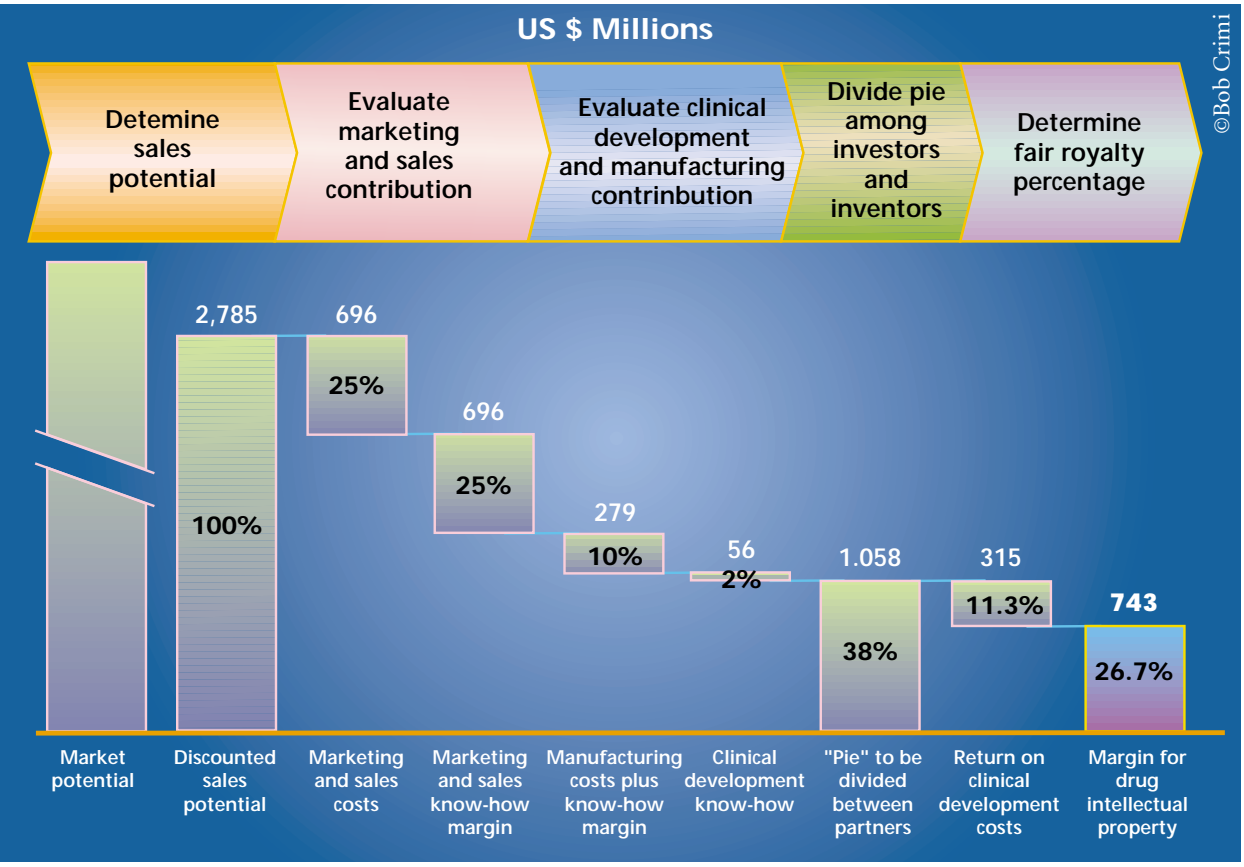

Figure 1. Financial compensation for the contributions of each deal partner. Each deal partner receives a percentage of the product's sales because of its contribution to the deal value. First, overall market potential is determined. Second, percentages are allocated, based on industry averages, to the contributions in marketing and sales, development, and manufacturing. Third, the investment contribution of the pharma company for clinical development is calculated, using the formula for determining risk-adjusted cost of capital. The remaining value equals the IP contribution, which is usually made solely by the biotechnology company.

\section{The right valuation}

The financial terms of any deal undeniably hold the key to the economic success of the deal for one or both partners, and are usually subject to tough negotiations. Thus, each party tries to convince the other that it deserves the lion's share of the potential financial rewards. These discussions are not always based solely on facts, can be arbitrary, and often lead to mutual resentments, which might end promising partnerships before they even begin.

In our interviews with $44 \mathrm{CEOs/busi-}$ ness developers from representative international pharmaceutical and biotechnology companies, only two thirds claimed to employ an economically valid, communicable evaluation methodology. Of the remaining one third, $21 \%$ still use "cost plus" approaches (adding an arbitrarily chosen margin to their expected cost), and $12 \%$ admit to determining financial deal terms based on best guesses.
In any case, it is clear that any negotiations intended to account for risk in a drug development deal should include the following two elements: first, an estimate of the total value of projected revenues from the deal (i.e., the sales potential); and second, a valuation of the contribution of each partner as a percentage of sales, using a risk-adjusted return formula that takes into account the fact that risk decreases as the compound is developed.

This approach has already proved its suitability for several companies with whom we have worked. In one case, it increased the valuation of the biotech startup's lead $\mathrm{R} \& \mathrm{D}$ project by a factor of five, from $\$ 10$ million to $\$ 50$ million.

\section{Estimating sales potential}

The first step in determining how to value the respective contributions of pharmaceutical companies and biotechnology companies is to estimate the size of the whole "pie" to be divided by the partners-namely, the rev- 


\section{Reengineering a historic biopharmaceutical deal}

The 1990 3TC deal between the medium-sized, Canadian biotech company Biochem Pharma (Laval, Quebec, Canada) and Glaxo (Wellcome) provides a dramatic demonstration of the difference that an appropriate deal valuation can make to a biotechnology company. The deal provides an ideal example for "reengineering" because most of the relevant figures are in the public domain.

Biochem Pharma's anti-HIV drug was licensed early, namely in a preclinical stage. As financial compensation for the worldwide marketing rights, Glaxo paid Biochem Pharma down payments of $\$ 1.7$ million, research fees of $\$ 2.6$ million per annum, and a total of $\$ 11$ million in milestones. In addition, the biotechnology company received royalties of $13 \%$ on sales. Triggered by its partnership with Glaxo, Biochem Pharma reached its operational break-even point in 1995 and a market cap in excess of $\$ 3$ billion only four years later, a success by any standards.

However, had Biochem Pharma followed our approach to valuation, its success would have been even more impressive. Applying pharmaceutical average numbers for success probabilities (i.e., $67 \%$ for phase III, $30 \%$ for phase II, $20 \%$ for phase I, and $10 \%$ for preclinical) and our formula for determining the value of financial investments, Biochem Pharma would have more than doubled its royalty rate-from the $13 \%$ it actually received to $26.7 \%$.

The financial consequences are equally significant: In 1998, alone, Biochem Pharma would have received $\$ 220$ million instead of $\$ 107$ million of the total sales of $\$ 824$ million. It's impossible to know what that would have meant in terms of today's valuation of the company, but certainly, such a dramatic increase in valuation can mean the difference between success and failure, especially for medium-sized biotechnology companies.

enues that will be generated by sales of the drug throughout its lifetime.

One can gain a rough estimate of the future sales potential by taking a top-down approach, estimating the total size of the market, and multiplying that by the expected market share of the product. For example, let's say you are developing an antidiabetic drug that is expected to capture about $5 \%$ of the oral antidiabetic market by 2005 . The estimated market volume by 2005 in this category is about $\$ 11$ billion, which would result in a sales potential of about $\$ 550$ million. This top-down approach can thus be used to provide a rough estimate, which you can then fine-tune through a bottom-up approach.

First, estimate the number of potential patients. Commonly used data sources are medical/epidemiological literature, analyst reports, and expert interviews, which provide information on disease prevalence, diagnosis and treatment rate, mortality, and compliance for a given year. Combine analysts' estimates on market growth and assumptions on market penetration and price to generate an initial forecast representing the sales potential of the drug. Use the discounted cash flow (DCF) method to discount the yearly cash flow with an appropriate discount (interest) rate to arrive at the present value of the product's future sales at the time of the product's launch ${ }^{1,2}$. These calculations yield an estimate of the product's sales potential. The first column of Figure 1 illustrates this calculation for the deal between Biochem Pharma (Quebec, Canada) and Glaxo Wellcome (London, UK).

\section{Partner contributions}

Once the sales potential has been established, it is necessary to allocate a percentage of that potential to the contributions of each partner. There are generally four areas of contribution to be valued: (1) research and discovery (2) clinical development (3) manufacturing, and (4) marketing and sales. Usually the biotechnology company contributes $\mathrm{R} \& \mathrm{D}$, whereas the pharmaceutical company usually contributes the other three areas.

The first step for most biotechnology companies is to attempt to value their IP before entering into negotiations. However, as we will explain more fully later, it's nearly impossible to value IP in a vacuum, without the context of the marketplace and the contributions of the pharma partner. Therefore, the contributions from the pharmaceutical company should be calculated first.

\section{Marketing and sales contribution}

Many biotechnology companies can find it challenging to value the sales and marketing contributions made by their pharmaceutical partners, and yet they must be able to do so in order to negotiate a fair deal. Thus, they must be able to calculate the size and cost of the sales force that will be required to market and sell their compound.

There are two elements to marketing and sales contributions: first, the costs associated with building up, training, and maintaining a sales force; and second, the know-how of that sales force in terms of skills and capabilities, reputation, and established customer access. In each case, the industry average will provide a guideline for determining the contribution.
An industry average for marketing and sales cost in pharma companies is $25 \%$ of sales. This figure acknowledges that pharmaceutical marketing and sales costs can vary a lot throughout the different life cycle stagesfrom up to $50 \%$ of net sales during launch down to $5 \%$ during a product's final stages.

However, to determine the appropriate marketing know-how contribution for the pharma partner, detailed data about its sales force are required, namely about number of representatives in the area of interest and their productivity. Usually, the marketing and sales margin compensating for sales force know-how falls somewhere between $5 \%$ and $25 \%$ of the sales potential, with $25 \%$ being a reported industry maximum (applying, e.g., to cocommercialization deals between top 10 pharma companies), and 5\% being the minimum.

\section{Manufacturing contribution}

Depending on the degree of sophistication of the manufacturing process and the pricing of the final product, the percentage of sales granted to the party that supplies the drugs to be used in clinical trials and the markets can vary a great deal. Industry data show that manufacturing costs for the pharmaceutical industry usually equal approximately $10 \%$ of sales. For biotechnology companies, manufacturing costs generally equal $15 \%$ of sales.

The relative manufacturing costs are higher because biotechnology companies usually manufacture more complex products, and sales are usually lower because the patient populations are smaller than those of pharmaceutical companies. In any case, these figures give a basis for compensating the value of manufacturing facilities and knowhow at between $10 \%$ and $15 \%$ of sales.

\section{Clinical development contribution}

The contributions in the area of clinical development - usually provided by the pharmaceutical partner-are one of the primary reasons that biotechnology companies pursue a deal. Once again, these contributions fall into two categories, know-how and financial investments. The former is much easier to value, again, based on industry averages. According to bids from clinical research organizations and targeted interviews, the clinical development know-how is usually rewarded with $2 \%$ of sales.

The pharmaceutical companies' financial investments are usually the larger component of their contribution in clinical development, and it is much more difficult to arrive at an appropriate value (in terms of sales percentage) for these contributions. To do so, it is necessary to take a venture capital approach, which rewards the pharmaceutical company for the appropriate degree of risk to the capital it invests. However, this is more challenging 
than it first appears, because the degree of risk actually declines as the compound progresses through the stages of clinical development.

Therefore, to arrive at an appropriate compensation rate for financial investments in clinical development, we have designed a formula that takes into account both the normal rate of return that the individual pharma company could expect on an investment, and a yield that reflects the decreasing degree of risk over time. For example, in the case of the Biochem Pharma-Glaxo deal (see "Reengineering a historic biopharmaceutical deal"), the normal rate of return was approximately 20\% (which equals Glaxo's return on investment (ROI) at that time). If this figure is not available, the pharma $\mathrm{R} \& \mathrm{D}$-specific weighted average cost of capital (WACC) of approximately $9 \%$ can be employed ${ }^{1}$.

To calculate more accurately the appropriate rate of return as risk declines, a new parameter-the risk-adjusted interest factor (RI) - needs to be determined, using the following formula:

$$
R I=\frac{1}{p_{t}} \times(1+W A C C)^{\left(Y_{l}-Y_{t}\right)}
$$

where RI is the risk-adjusted interest factor, $p_{t}$ is the success probability of the respective development stage, WACC is the weighted average cost of capital or normal rate of return, $Y_{l}$ is the projected year of launch, and $Y_{t}$ is the year of the respective development stage.

Using this interest factor, which is perfectly tailored for financial investments in the biopharmaceutical industry, it is possible to calculate the present value of investments that pharmaceutical companies make in the development of the product as it progresses toward launch. By adding up the resulting, discounted investments at different stages in drug development, the present value of the pharmaceutical company's investment in development can be calculated at the time of the product's launch, and the percentage of sales it represents can then be determined. In the Biochem Pharma case, this figure equaled $11.3 \%$ of sales (see Fig. 1).

\section{R\&D contribution}

Having considered all the other contributions to the biotechnology-pharmaceutical company deal, we now come to the R\&D contribution, which provides the impetus for the deal in the first place. Why, then, should it be valued last? Because, like gold in the ground, it has no intrinsic value until it is mined and made available to the market. The value of the gold is therefore what the market is willing to pay for the gold, minus the cost of removing it from the ground (which we have now calculated).

So, looking again at Figure 1, in our example, the residual value of the IP, after all the parties have been appropriately compen- sated for their contributions to developing and marketing it, is $26.7 \%$ of sales. In nearly all cases, this percentage would go to the biotechnology company, which normally has developed the compound at least up to clinical phase I. Biotechnology companies need to negotiate whether they want to receive this percentage as a percentage of sales over time, as a one-time payment (based on the present value of all sales), or as some combination of the two. They will make this determination based on their need for cash.

In some instances, the pharmaceutical company contributes its own know-how to develop, for example, a target into a compound (e.g., the Bayer (Leverkusen, Germany)-Millennium Pharmaceuticals (Cambridge, MA) deal of 1998 in highthroughput screening and lead refinement). In these cases, the residual value $(26.7 \%$ in our example) should be appropriately divided between the two partners, depending on how much each contributes to R\&D.

If we look at the history of biopharmaceutical deals, most biotechnology companies would have benefited from using the calculation we have just described to determine royalties. In our example, the deal for the antiviral agent $2^{\prime}, 3^{\prime}$-dideoxy- $3^{\prime}$-thiacytidine (3TC) between Biochem Pharma and Glaxo Wellcome would have resulted in a royalty rate twice as high as what it actually got (see "Reengineering an historic biopharmaceutical deal").

Looking ahead, what does this calculation mean for royalties in the future? As is so often the case, it depends. If the sales potential for the particular product is especially promising, while time-to-market, investments needed, and associated development uncertainty are rather low, royalty rates of up to $35 \%$ appear to be reasonable. However, if sales potential is not even close to blockbuster class, and development risk is known to be high, the appropriate royalty rate might even be lower than $5 \%$ for phase II deals.

\section{Appropriate control of IP rights}

As we mentioned earlier, placing a financial value on the contributions of each party is often the most hard-fought part of any negotiation. However, awarding appropriate control of IP rights can be equally important to the participants and to the success of the deal.

The current frantic activities of global pharma giants preparing for the patent expiration of their blockbuster drugs underscores the tremendous importance of IP in the pharma markets. Between 2000 and 2004, drugs generating revenues of a total of $\$ 43$ billion will see their US patents expire or lose market exclusivity under US Federal Drug Administration (Rockville, MD) rules. The consequences could not be harsher: Sales of brand-name drugs drop as much as $80 \%$ in the first year after their patents expire ${ }^{3}$ as a result of the introduction of generics, and can drop by as much as $95 \%$ in the ensuing years, as happened with Syntex's (Palo Alto, CA) Naprosyn, the patent for which expired in 1993.

As these examples show, control of IP represents an enormously powerful lever with huge economic consequences. Consequently, it is surprising to find that in most biopharmaceutical deals the biotechnology partner retains only the scientifically interesting rights (e.g., the right to publish scientific papers), whereas the pharma partner gets the complete patent ownership, including economically crucial rights (e.g., the right to comarketing) in more than $60 \%$ of all cases ${ }^{4}$.

Although this situation might initially leave pharmaceutical company representatives cheering about their impressive negotiation successes, their jubilation should be short-lived. The latest findings ${ }^{4}$ suggest that biopharmaceutical deals are much more successful for both partners over the long term if the biotechnology company retains the appropriate amount of the intellectual control rights. Historically, the approval rate is highest $(38 \%)$ in cases where the pharmaceutical company was assigned half of the possible 25 control rights or less, and only 15\% where the pharmaceutical company received 19-25 of the control rights ${ }^{5}$. This makes sense in light of the fact that only when both parties retain a fair stake in the deal can they be expected to exert their resources on its behalf.

Just as financial deal terms must reflect the contributions of each party, so control of IP must be correlated with each party's contributions to the development of the drug. In other words, the partner who will manufacture the product should get or retain the rights to do so. Generally speaking, the allocation of IP control rights should allow each partner to keep control of the steps carried out under its supervision. Furthermore, the distribution pattern should provide incentives for both partners to stay interested in the long-term success of the project.

\section{Good deals make for good business}

We've described an approach that fairly values deals and that will, over the long run, give biotechnology companies a more appropriate reward than they generally get for their contributions (see "Reengineering a historic biopharmaceutical deal"). How can biotechnology executives convince pharmaceutical companies to be interested in such an approach? And why would successful biotechnology companies change their current procedures? According to Steve Holtzmann, chief business development officer at Millennium, "Licenses are, initially, ladders you must climb; later, bridges you choose to build; always, structures that must contribute to the realization of your long- 
FEATURE

term vision and mission." Holtzmann uses that apt analogy to illustrate the changing challenges of deal making in biotechnology.

In negotiating their first deals, biotechnology companies face a huge "Catch-22." Because they don't have track records, they are often forced to compromise on deal terms, even if they own unique, world-class IP. Even companies like Millennium experienced these harsh times before it could demand, and get, premium deal conditions.

Only after they have proved themselves to be reliable, engaged partners who can contribute success-bearing technologies or products will most biotechnology companies find themselves in a position to negotiate deals that make sense for them-to "build the bridges" to partners of their choice and demand the terms that will reward them appropriately for their contributions.

However, as Holtzmann suggests, it is in the best interest of both biotechnology companies and their pharmaceutical partners to make deals that make sense from the beginning, regardless of negotiating leverage. Why? Because biotechnology companies who shortchange themselves in their initial deal make it even more difficult to make the right deals later. Either they will face demands from subsequent potential partners for com- parable terms, or they will face internal resistance from senior managers unwilling to sacrifice their vision to their internal business development department. And pharmaceutical companies that force biotechnology newcomers to accept unfavorable deal conditions will subsequently be spurned as poor partners by just the companies they will want to woo-successful biotechs.

And finally, the ultimate success of any deal depends on the continuing efforts of each party. Pharmaceutical companies gain little if biotechnology ventures are not excited enough about the deal to support it with the research efforts needed to make it successful. Similarly, biotechnology companies have little to gain if their deals leave the pharma companies with margins insufficient to motivate them to provide their best sales and marketing efforts.

The ultimate success of the deal thus depends on having two motivated partners, and only deals that fairly reward partners for their contributions can truly have that effect. The fruits of these true partnerships could be tremendous. More potent long-term alliances between biotechnology and pharmaceutical companies with fairer deal terms would guarantee biotechnology ventures more of the financial security they so desper- ately seek. At the same time, pharmaceutical companies entering true partnerships would make deals that increase their attractiveness as deal partners, dramatically increasing their access to the most promising projects available from biotechnology companies. Aren't these goals, after all, what both parties want to achieve in the first place?

1. An appropriate discount rate for pharma could be for example, a pharma-marketing-specific weighted average cost of capital (WACC) of $9 \%$. The rationale for using $9 \%$ is as follows: Grabowski and Vernon ${ }^{2}$ have suggested a $12 \%$ WACC for the pharmaceutical industry in general. In essence, they arrived at this figure by taking the risk-free rate of return on a 30 -year US Treasury bond, which is $6 \%$, and adding $3 \%$ for development risk and $3 \%$ for sales (market) risk. However, since we are valuing market risk here, it would be inappropriate to include development risk. Therefore, we end up with $6 \%$ (the risk-free interest rate) plus 3\% (the pharma market risk), which gives a total of $9 \%$.]

2. Grabowski, H.G. \& Vernon, J.M. A new look at the returns and risks to pharmaceutical R\&D. Management Sci. 36, 804-821 (1990).

3. Harris, G. How Merck plans to cope with patent expirations. Wall Street Journal, February 9, A1 (2000).

4. Lerner, J. The control of technology alliances: an empirical analysis of the biotechnology industry. $J$. Ind. Econ. 46, 125-156 (1998)

5. Lerner, J \& Tsai, A.I. "Financing R\&D through alliances: contract structure and outcomes in biotechnology" in Proceedings of Allicense '99: Banking on innovation in the next millennium (Recombinant Capital and Wilson, Sonsimi, Goodrich \& Rosati, San Francisco, 1999). 